\title{
Scale-dependent effects of climate on two copepod species, Calanus glacialis and Pseudocalanus minutus, in an Arctic-boreal sea
}

\author{
Jonas Persson ${ }^{1,3}$, Leif Chr. Stige ${ }^{1}$, Nils Chr. Stenseth ${ }^{1, *}$, Nikolay Usov $^{2}$, \\ Daria Martynova ${ }^{2}$
}

${ }^{1}$ Centre for Ecological and Evolutionary Synthesis, Department of Biology, University of Oslo, Postboks 1066, Blindern, 0316 Oslo, Norway

${ }^{2}$ White Sea Biological Station, Zoological Institute, Russian Academy of Sciences, Universitetskaya nab., 1, 199034, St. Petersburg, Russia

${ }^{3}$ Present address: Norwegian Institute for Water Research (NIWA), Gaustadalléen 21, 0349 Oslo, Norway

\begin{abstract}
Climate-driven changes in the phenology and composition of plankton affect ecosystem structure and function, but knowledge about such changes is limited by the scarcity of highquality, high-resolution, long-term monitoring data. Using a high-resolution observation series from the White Sea, spanning $>50 \mathrm{yr}$, we explored how water temperature and salinity influenced 2 key copepod species, Calanus glacialis and Pseudocalanus minutus. The results of the analysis depended critically on the temporal and life-stage resolution of the analysis. Copepod biomass was negatively correlated with salinity, but not correlated with temperature, when using annually aggregated data. However, salinity showed very small effects at a monthly resolution, failing to support a causal effect of salinity. On the other hand, temperature did show effects: in warm years, the biomass of C. glacialis increased earlier in spring and declined earlier in autumn. Analysis of stage-resolved data revealed a new level of complexity. The increase of biomass in spring at warmer temperatures mainly consisted of young life stages, whereas the decrease in autumn was mainly caused by reductions in older life stages. Temperature affected the phenology of several life stages of $P$. minutus, but not its total biomass, implying that climate effects on different life stages cancelled each other out. We argue that such climate-driven fluctuations in zooplankton phenology and age structure are likely to influence the role of the zooplankton as predators, competitors and prey, but that these effects of climate could remain unnoticed when using the coarser resolution of many sampling programs.
\end{abstract}

KEY WORDS: Scale dependence $\cdot$ Copepods $\cdot$ Developmental stages $\cdot$ Temperature $\cdot$ Marine White Sea $\cdot$ Phenology $\cdot$ Generalized additive modelling

\section{INTRODUCTION}

One of the largest uncertainties in predicting the ecological impacts of climate change is our incomplete understanding of ecological cause-and-effect relationships. The complexity of many interacting processes limits our ability to predict the future accurately based on observed trends. Temperature in- crease has been shown to affect the distribution, seasonal dynamics and composition of species (reviewed by Walther et al. 2002). The compositional changes include a general trend towards dominance of smaller organisms at warmer temperatures (Daufresne et al. 2009), which is in accordance with the ecological rules describing temperature-size relationships (i.e. Bergmann's rule, James' rule and the 
temperature-size rule), although the mechanisms causing such a shift are not clear. Changes in the structure of marine ecosystems can affect their function, which, in turn, may feed back on the structure. For example, shifts in the timing and size spectra of prey (copepods) influence the survival of juvenile cod (Munk 1997, Beaugrand et al. 2003), a key species in many North Atlantic shelf systems. In order to understand how climate affects the dynamics of marine ecosystems, it is therefore important to consider the associated changes in ecosystem structure, which requires data with sufficient resolution in space, time (season) and species' stage and size composition.

In recent decades we have seen significant changes in the distribution and phenology of zooplankton. For example, the copepod biomass peak in the Central North Sea has advanced by $10 \mathrm{~d}$ in 45 yr (reviewed by Richardson 2008). In the Arctic, changes in the circulation and temperature of water and air, as well as changes in ice cover, have been shown to lead to increased primary production and altered zooplankton species composition (reviewed by Wassmann et al. 2011). However, detailed studies of how climate affects zooplankton phenology in Arctic and sub-Arctic areas are scarce. In high-latitude ecosystems, large copepod species are rich in nutrients and thus compose vital parts of the food chains (FalkPetersen et al. 2007), underlining the need for such knowledge. Copepods molt through several juvenile stages of gradually increasing size before they become adults. Because of the importance of prey size for predators (Munk 1997), it is of particular interest to understand how climate influences the dynamics of the individual life stages and thus the age structure of each copepod species. For practical reasons, many zooplankton studies have used aggregated species data, i.e. total biomass or total abundance, which overlooks population age structure.

In the present study, we analyze a unique longterm (since 1964) observation series of zooplankton and hydrological parameters obtained at the White Sea Biological Station of the Zoological Institute, Russian Academy of Sciences (Berger et al. 2003). This dataset has several qualities which are uncommon in studies of climate effects on zooplankton (see recent reviews by Richardson 2008, Ji et al. 2010, Mackas \& Beaugrand 2010), it is from a sub-Arctic location and is characterized by a long period of observation and high sampling frequency $(47 \mathrm{yr}$, up to 3 samples $\mathrm{mo}^{-1}$ ). In addition, the copepods are separated into life stages, providing unique resolution for the study of the environmental effects on copepod life cycles.
The aim of the present study is to examine the response of Calanus glacialis and Pseudocalanus minutus populations to year-to-year changes in water temperature and salinity. C. glacialis and P. minutus are key species in the White Sea (Prygunkova 1974, Pertsova \& Kosobokova 2010, Berger et al. 2003). C. glacialis spawns in waters all around the Arctic shelf and in the White Sea. It is a relatively large (Table 1), Arctic, cold-water species (Jaschnov 1970) characterized by a 2 to 5 yr life cycle (Søreide et al. 2010 and references therein). C. glacialis can account for up to $80 \%$ of zooplankton biomass in the Arctic shelf seas and plays a key role in the pelagic lipid-based Arctic food webs due to its very high lipid content (>70\% lipids of dry weight; Søreide et al. 2010 and references therein). C. glacialis copepodite stage $\mathrm{C} 4$ and C5 overwinter in diapause. P. minutus is a smaller (Table 1) and more wide-ranging species that can be found in both temperate and Arctic waters and is most abundant on shelves (Frost 1989). P. minutus is characterized by a 1 yr life cycle and also diapauses during winter. $P$. minutus was one of the most abundant active sub-ice species near the study area, whereas only low numbers of $C$. glacialis were found there (Melnikov et al. 2005). The life cycles of both $C$. glacialis and P. minutus include 6 naupliar (here considered as 1 group, nauplii) and 6 copepodite stages (C1 to C5, adults).

First, we explore the zooplankton-environment correlations using data aggregated on an annual scale, then the environmental effects on the seasonal pattern in total species biomass and, finally, the environmental effects on the seasonal pattern of each individual life stage within each species. Our results provide novel information on the mechanisms through which climate influences zooplankton population dynamics, phenology and age structure, while illustrating how effects can go undetected if the data are aggregated too coarsely.

Table 1. Calanus glacialis, Pseudocalanus minutus. Individual dry weight (mg) of C. glacialis and P. minutus in the White Sea (Prygunkova 1970)

\begin{tabular}{|lcc|}
\hline Stage & C. glacialis & P. minutus \\
\hline Nauplii & 0.01 & 0.01 \\
Copepodite 1 & 0.03 & 0.02 \\
Copepodite 2 & 0.06 & 0.04 \\
Copepodite 3 & 0.13 & 0.04 \\
Copepodite 4 & 0.44 & 0.06 \\
Copepodite 5 & 1.19 & 0.07 \\
Adult males & 3.80 & 0.08 \\
Adult females & 4.00 & 0.08 \\
\hline
\end{tabular}




\section{MATERIALS AND METHODS}

\section{Time series}

The White Sea Biological Station of the Zoological Institute (Russian Academy of Sciences) has monitored zooplankton abundance, water temperature and water salinity in the White Sea on a regular basis from 1964 to present. The sampling point (' $\mathrm{D}-1$ station' in Fig. $1^{\prime} 66^{\circ} 19^{\prime} 50^{\prime \prime} \mathrm{N}, 33^{\circ} 40^{\prime} 06^{\prime \prime} \mathrm{E}$, depth $65 \mathrm{~m}$ ) is located in the Chupa Inlet of Kandalaksha Bay. The samples were taken every $10 \mathrm{~d}$ during icefree periods and monthly from stable ice cover. Zooplankton were sampled with a standard Juday net $\left(0.1 \mathrm{~m}^{2}\right.$ mouth opening, $168 \mu \mathrm{m}$ mesh size) at standard water layers of 0 to 10,10 to 25 and 25 to $65 \mathrm{~m}$ (depth intervals 1 to 3 , respectively). The zooplankton sampling and counting were performed according to standard methods (Zhadin 1960, Tsyban 1980, Harris et al. 2000). Smaller stages were probably under-sampled by the mesh size used; however, this was constant over the entire sampling period and should not have introduced any time-varying bias. Water temperature and salinity were measured at depths of $0,5,10,15,25,50$ and $65 \mathrm{~m}$.

The zooplankton abundance data were recalculated into biomass (mg dry weight, DW) using previously established stage-specific values (Table 1). The weights were arrived at by placing 30 to
50 individuals of each stage onto separate preweighted filters (3 to 5 replicates), rinsing the filters with filtered seawater and a small volume of distilled water, drying at $60^{\circ} \mathrm{C}$ for $24 \mathrm{~h}$, cooling in a desiccator and weighing again (Prygunkova 1970). This conversion had no practical effect on the analysis of individual life stages but allowed the calculation of total biomass as an integrated measure of all stages. Note, however, that this conversion neglects possible changes in condition and that stage weight can vary with temperature, e.g. for Pseudocalanus elongatus (Klein Breteler \& Gonzalez 1988), though not found for Calanus glacialis (Escribano \& McLaren 1992). The dataset was recalculated into depth-integrated biomass per $\mathrm{m}^{2}$ and monthly mean values for each year. Annual mean biomass was calculated from monthly values, after replacing missing values $(17 \%$ of the data) by the monthly means across all years. Water column mean temperature and salinity were calculated by weighting the readings at different depths by the lengths of the depth intervals covered. 'Ambient' temperature and salinity of a given species and stage were defined as the temperature and salinity at the measurement depth closest to its monthly biomass-weighted mean depth (Table 2). The biomass-weighted mean depth, $D$, was calculated as $D=\Sigma\left(b_{i} d_{i}\right) / \Sigma b_{i}$, where $b_{i}$ and $d_{i}$ are, respectively, the biomass and mean depth for depth interval $i$ ( $i=1$ to 3 ).

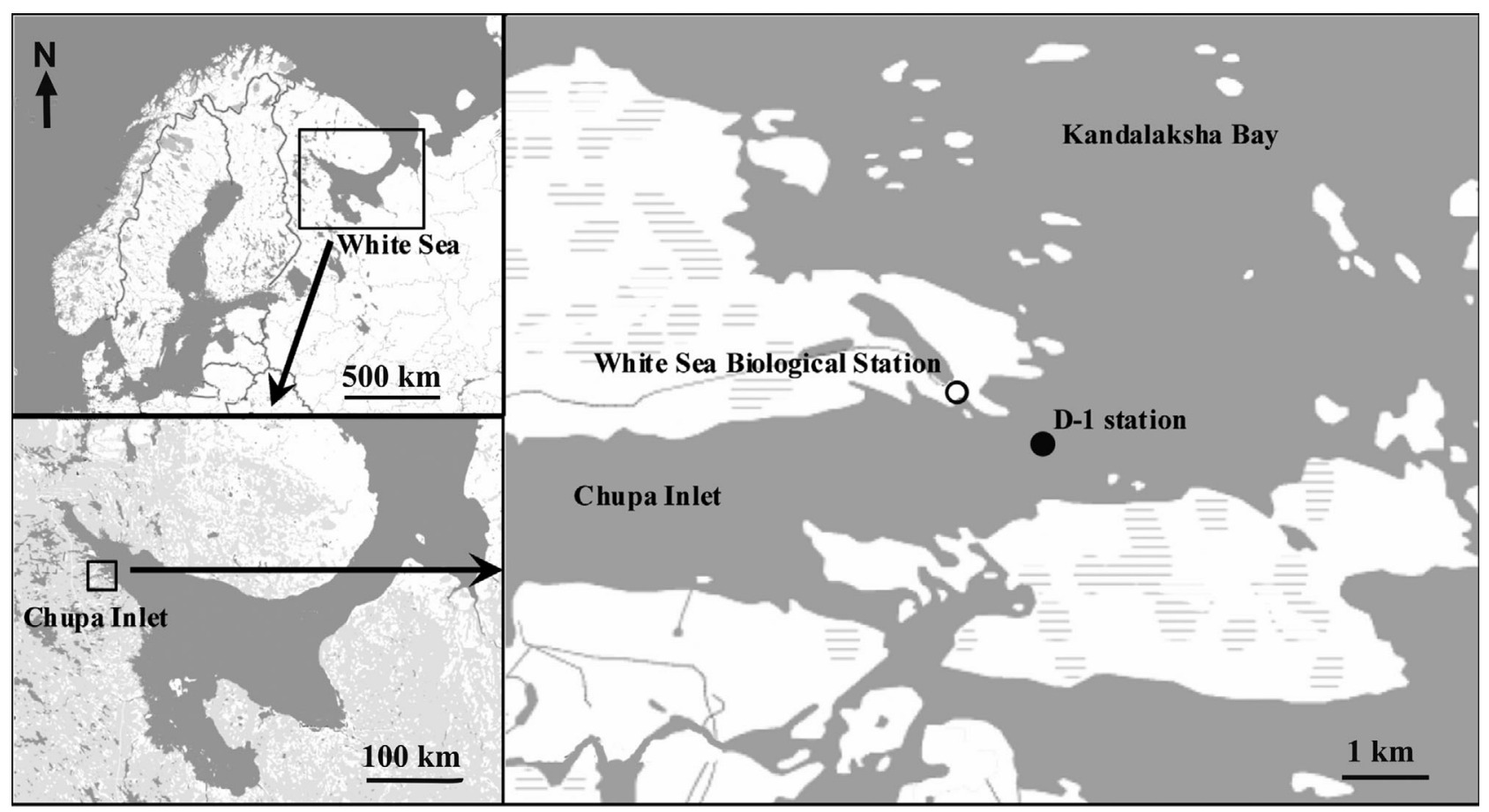

Fig. 1. Map of the area showing the location of sampling station D-1 (66 $\left.16^{\circ} 50^{\prime \prime} \mathrm{N}, 33^{\circ} 40^{\prime} 06^{\prime \prime} \mathrm{E}\right)$ 
Table 2. Calanus glacialis, Pseudocalanus minutus. Mean biomass-weighted depths $(\mathrm{m})$ of the 2 copepod species

\begin{tabular}{|lcc|}
\hline Month & C. glacialis & P. minutus \\
\hline 1 & 24 & 22 \\
2 & 22 & 20 \\
3 & 25 & 13 \\
4 & 24 & 10 \\
5 & 12 & 11 \\
6 & 21 & 18 \\
7 & 34 & 30 \\
8 & 40 & 34 \\
9 & 41 & 31 \\
10 & 39 & 26 \\
11 & 37 & 27 \\
12 & 37 & 26 \\
\hline
\end{tabular}

\section{Statistical analysis}

Zooplankton seasonal trends were analyzed using generalized additive modeling (GAM; Wood 2006) with the 'mgcv' library (v.1.6-2; Wood 2006) in R (v.2.11.1; R Development Core Team 2010). The natural logarithm of the biomass ( $\mathrm{mg} \mathrm{DW} \mathrm{m}^{-2}$ ) was modeled as a function of season (month), temperature, salinity and the biomass of the previous month (of the same species, and, in stage-resolved analysis, the same or a younger stage, see below). Biomass of the previous month was included as a predictor variable to more accurately quantify the effects of temperature and salinity on the increment in biomass from one month to the next. For months with no samples in the previous month (10\% of the cases), the previous month's biomass value was imputed by the mean value for that month. All explanatory variables were centered (their mean equaling zero). The model formula was:

$$
\begin{aligned}
y_{i j}= & \alpha+f\left(\text { month }_{j}\right)+g\left(\text { month }_{j}\right) \bar{y}_{i(j-1)}+ \\
& h\left(\text { (month }_{j}\right) \cdot T_{i j}+k\left(\text { month }_{j}\right) \cdot S_{i j}+\varepsilon_{i j}
\end{aligned}
$$

Here, $y_{i j}$ is the $\ln$ (biomass +1 ) of a given stage (or total biomass) of Calanus glacialis or Pseudocalanus minutus for month $j$ in year $i_{i} \alpha$ is a constant; $f, g, h$ and $k$ are smoothing functions (cyclic cubic regression spline functions with maximally 5 knots, i.e. 4 degrees of freedom) of month $(1,2, \ldots, 12) ; \bar{Y}_{i(j-1)}$ is the observed ln(biomass +1 ) of either the same stage or a previous stage lagged 1 mo and the overall mean subtracted for that month; $T_{i j}$ is the ambient temperature anomaly, $S_{i j}$ is the ambient salinity anomaly, and $\varepsilon_{i j}$ is a normally distributed and independent noise term. In order to select which life stage to include as a covariate $\left(\bar{y}_{i(j-1)}\right.$, Eq. 1), we have compared the models with the lagged version of the response variable or each of the younger life stages and then selected the formulation providing the lowest value of Akaike's information criterion (Burnham \& Anderson 2002)

In order to assess the variability of seasonal patterns of zooplankton biomass in response to the temperature factor only, we inspected the predictions from simplified models without the effects of salinity and biomass of the previous month (notation as above):

$$
y_{i j}=\alpha+f\left(\text { Month }_{j}\right)+h\left(\text { Month }_{j}\right) \cdot T_{i j}+\varepsilon_{i j}
$$

The interannual variation in temperature was higher in the warmer season, i.e. an increase of $2^{\circ} \mathrm{C}$ represents a more extreme change in winter than in summer; therefore, the predictions for a fixed temperature increase or decrease throughout the year might be misleading. In order to visualize the predicted effects of temperature, we show model predictions for the 10th, 50th and 90th percentiles of the ambient temperature for each month (representing cold, normal and warm years, respectively). The quantiles were estimated using quantile regression with the R libraries 'quantreg' (v.4.53; Koenker 2010) and 'splines' (R Development Core Team 2010).

To account for autocorrelation in significance tests of correlations between time series, the effective number of degrees of freedom was adjusted following a method proposed by Quenouille (1952) and modified by Pyper \& Peterman (1998):

$$
\frac{1}{N_{c}}=\frac{1}{N}+\frac{2}{N} \sum_{j=1}^{N / S} r_{X X}(j) \times r_{Y Y}(j)
$$

where $N_{c}$ is the number of independent joint observations on the time series $X$ and $Y, N$ is the sample size and $r_{X x}(j)$ and $r_{Y Y}(j)$ are the autocorrelation of $X$ and $Y$ at $\operatorname{lag} j$. The statistical significance of the correlation between $X$ and $Y$ was tested by a $t$-test with $\mathrm{df}=N_{c}-2$ degrees of freedom (or $\mathrm{df}=N-2$ if $N_{c}>N$ ).

\section{Residual diagnostics}

The residuals from the models describing Calanus glacialis and Pseudocalanus minutus (Eq. 2; Table 3) did not show strong deviations from the normal distribution (Fig. S1 in the supplement at www.int-res.com/articles/suppl/m468p071_supp.pdf), but did exhibit some temporal dependencies (Figs. S2 to S5). In particular, annual means of residuals from 2 models for C. glacialis (including that for total biomass) and 3 models for $P$. minutus indicated positive 
autocorrelation at $1 \mathrm{yr}$ lag (Figs. S4 and S5), indicating that some important unknown explanatory variables were not included in the model. This means that the models' $p$-values and confidence bands should be interpreted with caution. In order to assess the robustness of the results, we computed correlation tests between the total biomass of $C$. glacialis and the ambient temperature for $1 \mathrm{mo}$ at a time, correcting the degrees of freedom by accounting for positive autocorrelation in the time series. We found significantly negative correlations for February $(\mathrm{r}=-0.41, \mathrm{n}=33 \mathrm{yr}, \mathrm{df}=31, \mathrm{p}=0.02)$ and September $(\mathrm{r}=-0.69, \mathrm{n}=46 \mathrm{yr}, \mathrm{df}=38.9, \mathrm{p}<$ 0.0001). A negative correlation was observed on the border of statistical significance for November $(\mathrm{r}=$ $-0.31, \mathrm{n}=40 \mathrm{yr}, \mathrm{df}=37.2, \mathrm{p}=0.05)$, and a significantly positive correlation, for May $(\mathrm{r}=0.39, \mathrm{n}=$ $37 \mathrm{yr}, \mathrm{df}=33.1, \mathrm{p}=0.02)$. We therefore conclude that the reported results are unlikely to merely reflect statistical artifacts.

\section{RESULTS}

\section{Long-term trends}

The average temperature and salinity at the study site were $1.65^{\circ} \mathrm{C}$ and $27.0 \%$, respectively (Fig. 2). A cold period in the late 1960s was followed by a period with temperatures fluctuating around the norm in the 1970 s and early 1980 s, a warm period in the late 1980 s, a colder period in the 1990s and a warm period with 4 record-warm years in the 2000s (Fig. 2a). The running mean shows an overall increase. Salinity was above average for most years in the 1960s and 1970s, but then declined abruptly (Fig. 2a). Salinity was lowest during the 1980 s and early 2000s, with the running mean showing a slight increase after 1980. The total biomass of Calanus glacialis showed an overall increasing trend (Fig. 2b), while the total biomass of Pseudocalanus minutus initially rose towards a peak around 1990 which was followed by a decrease (Fig. 2b).

The changes in biomass of the different life stages reflect the changes in total biomass to various extents (Fig. 3). Most life stages of Calanus glacialis showed a trend of increase after the 1960s. For Pseudocalanus minutus, the long-term changes differ more between life stages. The biomass of $P$. minutus nauplii and males seems to have declined, especially during the last decade, while the biomasses of copepodite stages C3 to C5 increased during the 1980s and have slowly decreased since then.

The bulk of the Calanus glacialis population (in terms of total biomass) always occupied deeper water layers than Pseudocalanus minutus (Table 2).

Table 3. Summary of regression model results. Each line corresponds to one generalized additive model (Eq. 1). For each species and stage, the reduction in the model's total $\mathrm{R}^{2}$ when the explanatory variable is removed from the full model is given (partial $\mathrm{R}^{2}$ ). The statistical significance of the variable is indicated by: ${ }^{*} \mathrm{p}<0.05,{ }^{* *} \mathrm{p}<0.01$ and ${ }^{* * *} \mathrm{p}<0.001 ; \mathrm{n}=455$

\begin{tabular}{|c|c|c|c|c|c|c|}
\hline \multirow[t]{2}{*}{ Stage } & \multicolumn{5}{|c|}{ Predictors (partial $\mathrm{R}^{2}$ ) } & \multirow[t]{2}{*}{ Total $\mathrm{R}^{2}$} \\
\hline & Month & Lag-biomass & Lag-stage & Temperature & Salinity & \\
\hline \multicolumn{7}{|l|}{ Calanus glacialis } \\
\hline Nauplii & $0.38^{* * *}$ & $0.005^{*}$ & Nauplii & $0.02^{* *}$ & 0.00 & 0.41 \\
\hline Copepodite 1 & $0.39^{* * *}$ & $0.01^{* *}$ & Nauplii & $0.04^{* * *}$ & 0.00 & 0.44 \\
\hline Copepodite 2 & $0.48^{* * *}$ & $0.02^{* * *}$ & Nauplii & $0.03^{* * *}$ & 0.00 & 0.53 \\
\hline Copepodite 3 & $0.67^{* * *}$ & $0.03^{* * *}$ & Nauplii & $0.01^{*}$ & 0.00 & 0.70 \\
\hline Copepodite 4 & $0.45^{* * *}$ & $0.08^{* * *}$ & Copepodite 4 & $0.01^{* *}$ & $0.01^{*}$ & 0.55 \\
\hline Copepodite 5 & $0.39^{* * *}$ & $0.07^{* * *}$ & Copepodite 5 & 0.01 & 0.00 & 0.50 \\
\hline Adult males & $0.28^{* * *}$ & 0.01 & Adult males & 0.01 & 0.00 & 0.29 \\
\hline Adult females & $0.43^{* * *}$ & $0.02^{* * *}$ & Adult females & $0.04^{* * *}$ & $0.01^{*}$ & 0.53 \\
\hline Total biomass & $0.40^{* * *}$ & $0.10^{* * *}$ & Total biomass & $0.03^{* * *}$ & 0.00 & 0.55 \\
\hline \multicolumn{7}{|c|}{ Pseudocalanus minutus } \\
\hline Nauplii & $0.50^{* * *}$ & $0.02^{* * *}$ & Nauplii & $0.01^{* *}$ & 0.00 & 0.53 \\
\hline Copepodite 1 & $0.56^{* * *}$ & $0.02^{* * *}$ & Copepodite 1 & $0.01^{* *}$ & 0.00 & 0.59 \\
\hline Copepodite 2 & $0.60^{* * *}$ & $0.03^{* * *}$ & Copepodite 2 & 0.01 & 0.00 & 0.64 \\
\hline Copepodite 3 & $0.61^{* * *}$ & $0.05^{* * *}$ & Copepodite 3 & $0.02^{* * *}$ & 0.00 & 0.66 \\
\hline Copepodite 4 & $0.45^{* * *}$ & $0.08^{* * *}$ & Copepodite 4 & 0.00 & 0.00 & 0.54 \\
\hline Copepodite 5 & $0.66^{* * *}$ & $0.00^{*}$ & Copepodite 4 & $0.01^{*}$ & 0.00 & 0.67 \\
\hline Adult males & $0.50^{* * *}$ & $0.05^{* * *}$ & Adult males & $0.01^{*}$ & 0.01 & 0.54 \\
\hline Adult females & $0.72^{* * *}$ & $0.02^{* * *}$ & Adult females & 0.00 & 0.00 & 0.73 \\
\hline Total biomass & $0.70^{* * *}$ & $0.06^{* * *}$ & Total biomass & 0.00 & 0.00 & 0.77 \\
\hline
\end{tabular}



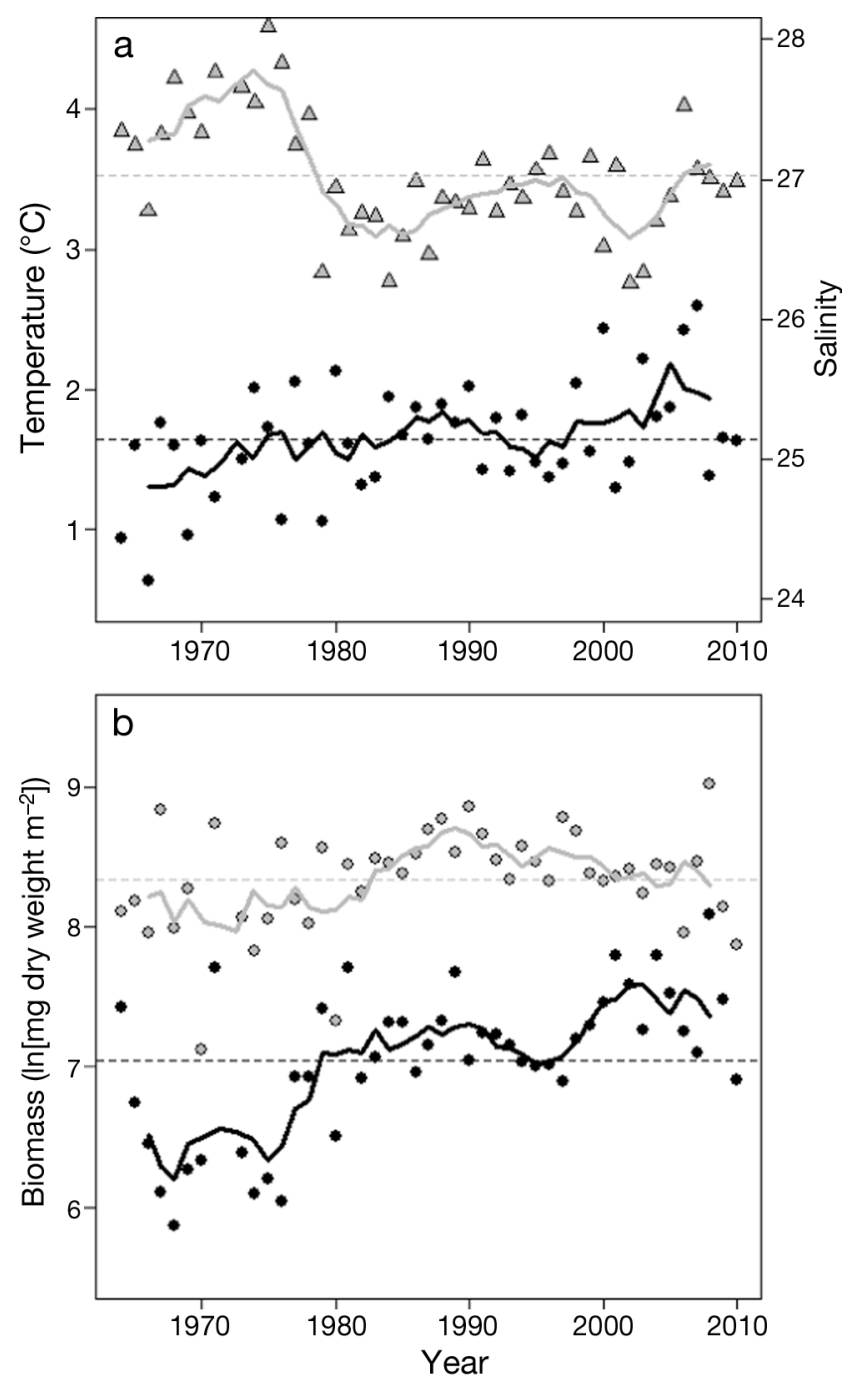

Fig. 2. Time series of (a) the annual mean temperature (black circles) and salinity (grey triangles) of the water column and (b) the annual total biomasses of Calanus glacialis (black circles) and Pseudocalanus minutus (grey circles). Dashed horizontal lines: overall mean values; thicker solid lines: 5 yr running means

\section{Climate-plankton biomass correlations at an annual scale}

Total biomass was not correlated with the change in the annual mean (ambient) temperature for either Calanus glacialis (Pearson's coefficient of correlation, $\mathrm{r}=0.00, \mathrm{n}=46 \mathrm{yr}$, degrees of freedom corrected for autocorrelation, $\mathrm{df}=31.9, \mathrm{p}>0.5$ ) or Pseudocalanus minutus $(\mathrm{r}=-0.09, \mathrm{n}=46, \mathrm{df}=35.0, \mathrm{p}>0.5)$. There was a tendency for negative associations between biomass and the annual mean salinity $(C$. glacialis: $\mathrm{r}=$ $-0.55, \mathrm{n}=46, \mathrm{df}=13.8, \mathrm{p}=0.03 ;$ P. minutus: $\mathrm{r}=-0.28$, $\mathrm{n}=46, \mathrm{df}=29.1, \mathrm{p}=0.13$ ).

\section{Climate effects on seasonal pattern in plankton biomass}

Using GAMs with seasonally varying coefficients (Eq. 1), we assessed the temperature and salinity effects on the seasonal patterns of zooplankton biomass. In these analyses, temperature was found to be a significant predictor for 6 out of 8 life stages, as well as for total biomass of Calanus glacialis and for 5 out of 8 life stages of Pseudocalanus minutus (Table 3). In contrast, salinity showed weaker overall effects, which failed to reach statistical significance for all but 2 life stages of C. glacialis. In order to investigate why salinity correlated with total C. glacialis biomass on an annual scale (see above), but not on a monthly scale, we fitted a series of models in which salinity values were shifted from 0 to 6 mo backward or forward in time relative to the period of observed biomass values. The current month's salinity showed no significant effect on the total biomass of $C$. glacialis (Table 3). Salinity values shifted either 1, 5, or 6 mo ahead of, or 1, 2, or 4 mo after biomass showed significant effects $\left(\mathrm{p}<0.05\right.$, changes in $\mathrm{R}^{2}$ ranging from 0.6 to $1.0 \%$, the strongest association being with the next month's salinity, for which $\mathrm{p}<0.01$ ). The strongest association was thus found between the biomass and the subsequent month's salinity, not supporting the causal effects of salinity on copepods.

The predicted patterns in total biomass of Calanus glacialis and Pseudocalanus minutus in cold, normal and warm years are based on the simpler model, which does not take into account the salinity and biomass of the previous month (Eq. 2; Fig. 4). In warm years, the biomass of C. glacialis is higher in spring and lower in autumn; the temperature thus predicts the timing of the zooplankton peak, but not the magnitude and duration of the peak. Variability of the total biomass of $P$. minutus shows a less pronounced response to temperature. The increase in C. glacialis biomass in spring during warm years was mainly caused by increased abundance of nauplii and young copepodite stages ( $\mathrm{C} 1$ to $\mathrm{C} 3$; Fig. 5), whereas the reduced biomass in autumn was mainly caused by reduced abundance of the older copepodite stages (C4 to C5, including adults; Fig. 5). With some exceptions, the copepodites of $P$. minutus showed minor responses to temperature, but, for example, in warm years there were less nauplii and $\mathrm{C} 1$ copepodites present in late summer and autumn; however, this change was not observed for the older copepodite stages.

The proportions of variance explained by temperature for the different life stages were low (maxi- 
Calanus glacialis
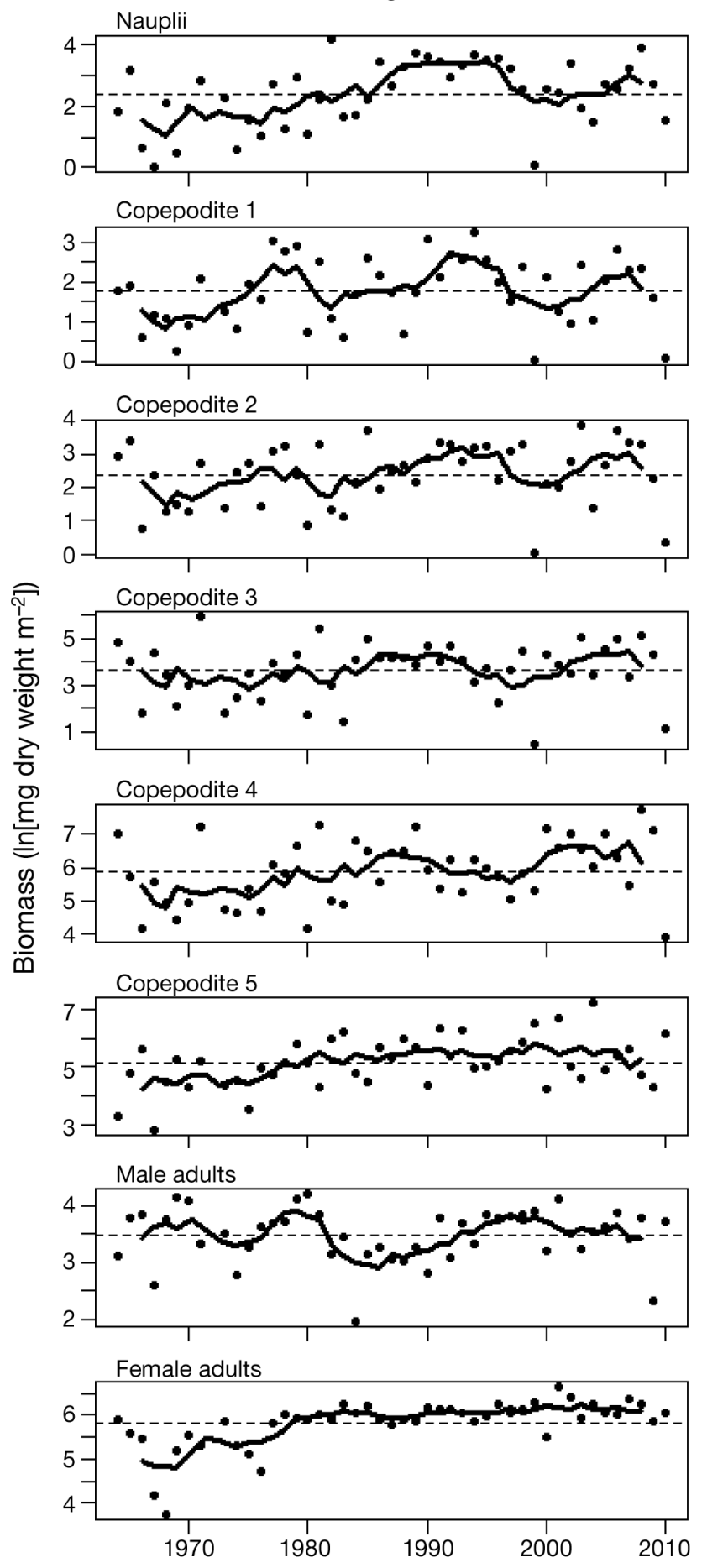

\section{Pseudocalanus minutus}
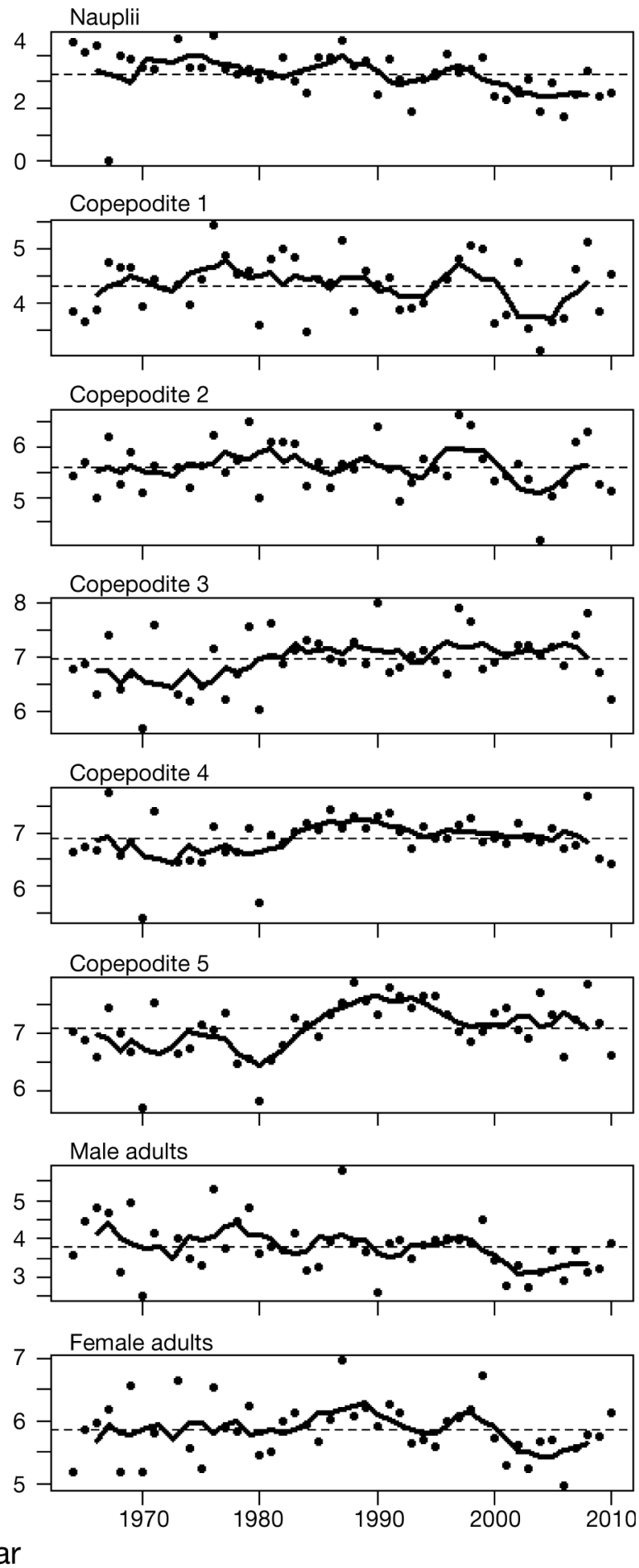

Fig. 3. Calanus glacialis, Pseudocalanus minutus. Time series of annual mean biomass of each individual stage of C. glacialis and $P$. minutus. Dashed horizontal lines: overall mean values; thicker solid lines: 5 yr running means

mum $4 \%$; Table 3 ), which partly reflected the fact that large parts of the variance in the data were seasonal (captured by the month effects; Table 3) rather than interannual. Table 4 shows for which month the biomass of each of the life stages displayed the proportionally largest temperature response, in terms of the predicted absolute change in biomass on the logged scale (see Table S1 in the supplement at 


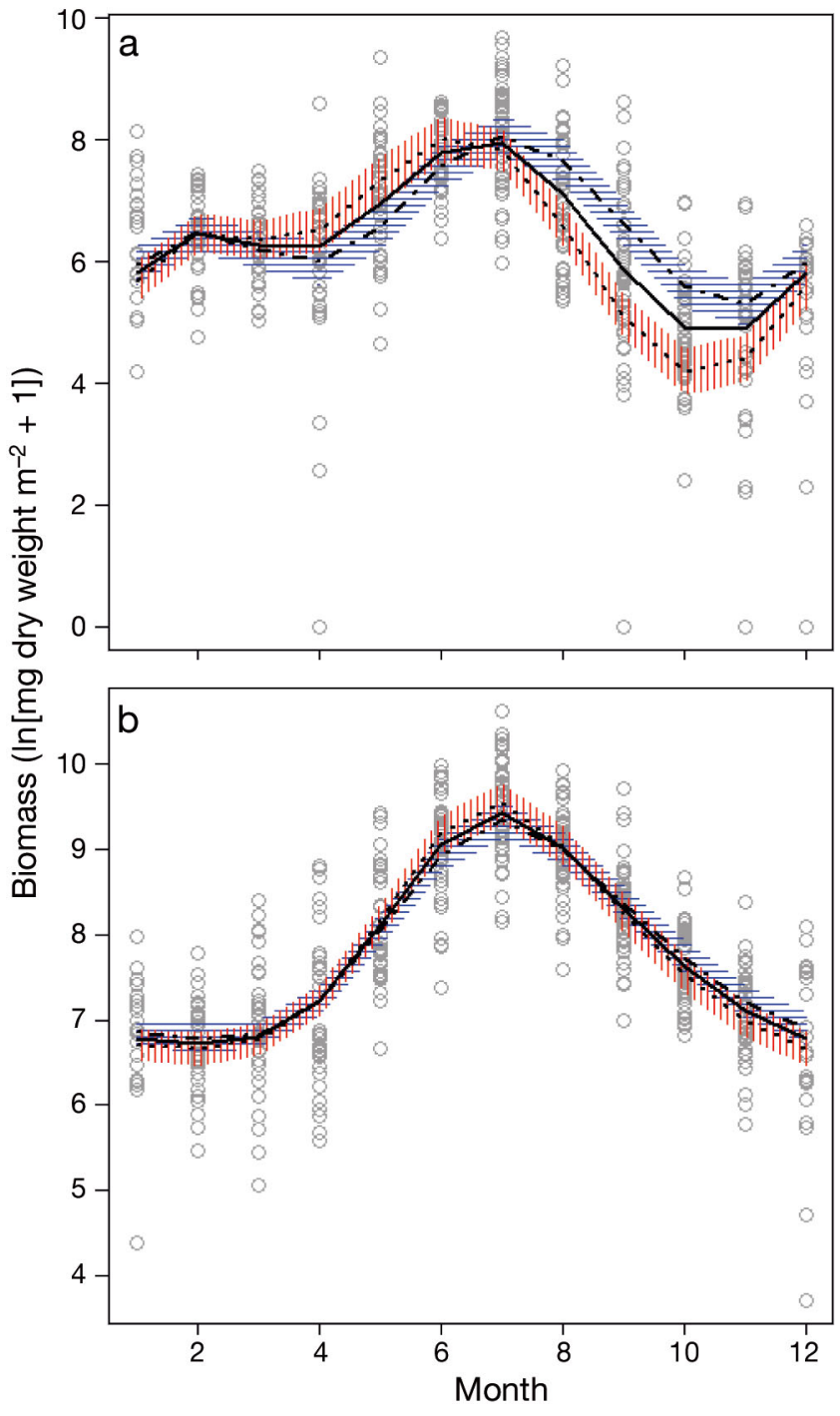

Fig. 4. Calanus glacialis, Pseudocalanus minutus. Seasonal pattern in total biomass predicted for normal, cold and warm years for (a) C. glacialis and (b) P. minutus. Normal-year mean (solid line; representing the 50th percentile of ambient temperature for each month), warm-year mean with a $95 \%$ confidence interval (dotted line and red vertically lined area; 90 th percentile) and cold-year mean with a $95 \%$ confidence interval (dotted/dashed line and blue horizontally lined area; 10th percentile) are shown. The original data points are included in the graphs as empty grey circles

www.int-res.com/articles/suppl/m468p071_supp.pdf for all months and calculation of differences). For the naupliar and early copepodite stages of Calanus glacialis, the most pronounced response was observed in spring and early summer, biomass then increased 3 -fold or even more when comparing a cold year (10th temperature percentile) to a warm year (90th temperature percentile). C5 copepodites and adults of C. glacialis exhibited the most pronounced re- sponse in autumn, when the biomass was reduced by two-thirds or more in a warm compared to a cold year. The largest differences for the predicted biomass of young life stages of Pseudocalanus minutus were found in spring and early summer, but the temperature effect varied among stages.

\section{DISCUSSION}

In this paper, we explored the effects of salinity and temperature on the seasonal dynamics of 2 copepod species using an unusually long and detailed timeseries dataset from a sub-Arctic location, the White Sea. We found that the results of the study, and therefore their interpretation, depended critically on the scale of the analysis: whether data were aggregated on a monthly or an annual scale and whether total biomass or the biomass of individual life stages were considered.

On an annual scale, we found a statistically significant negative correlation between salinity and Calanus glacialis biomass. However, when analyzing the data on a monthly scale, it turned out that this correlation was caused by associations at time lags that seemed inconsistent with causal effects of salinity per se. It is possible that these correlations reflect effects of a third unmeasured factor, such as ice cover, which influences both salinity and copepod dynamics. Early season changes in salinity are closely related to ice melt, which, in turn, corresponds closely to phytoplankton blooms. C. glacialis reproduction and early stage survival are highly dependent on early season food sources (Daase et al. 2007, D. Martynova et al. unpubl. data), and food shortage (e.g. caused by temporal mismatch) is likely to affect the number of offspring (Søreide et al. 2010). In contrast, for Pseudocalanus minutus, no correlations with salinity were found. This species is less dependent on the ice-melting period and starts to breed earlier than C. glacialis in the study area (Prygunkova 1974, Kosobokova 1999, Usov 2011). We speculate that the match between the food requirements of C. glacialis and the phytoplankton bloom is better in low-salinity years. However, without phytoplankton data we cannot separate this hypothesis and an alternative - that the correlation at the annual scale is spurious and arises by chance. The relatively stable salinity of marine environments seldom has significant effects on planktonic animals. The variability of salinity in deeper water layers seldom exceeds the optimal ranges of planktonic animals (Hopper 1960, Lance 1962). Even in seasonally ice-covered seas, which are character- 


\section{Calanus glacialis}

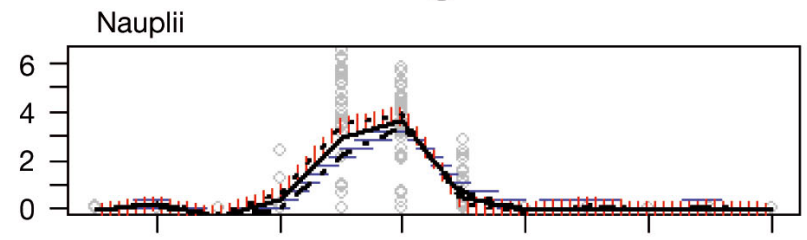

Copepodite 1

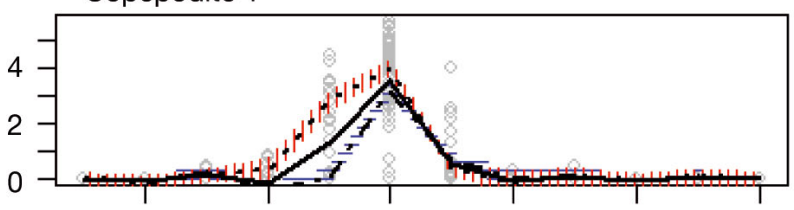

Copepodite 2
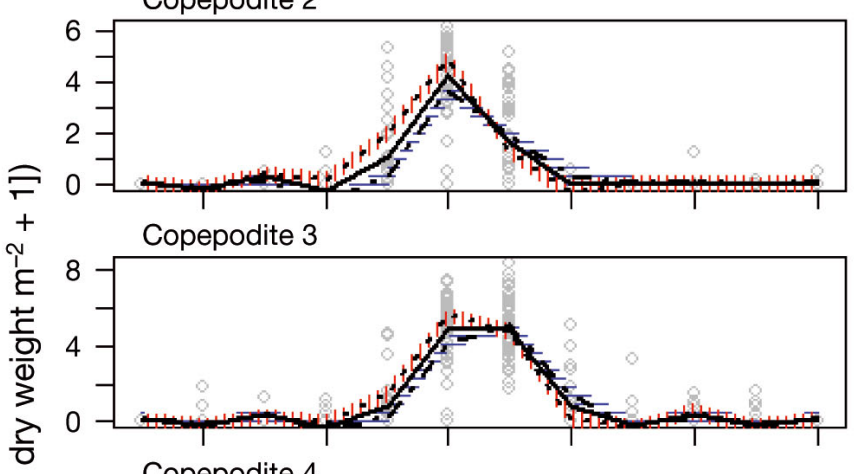

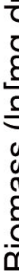
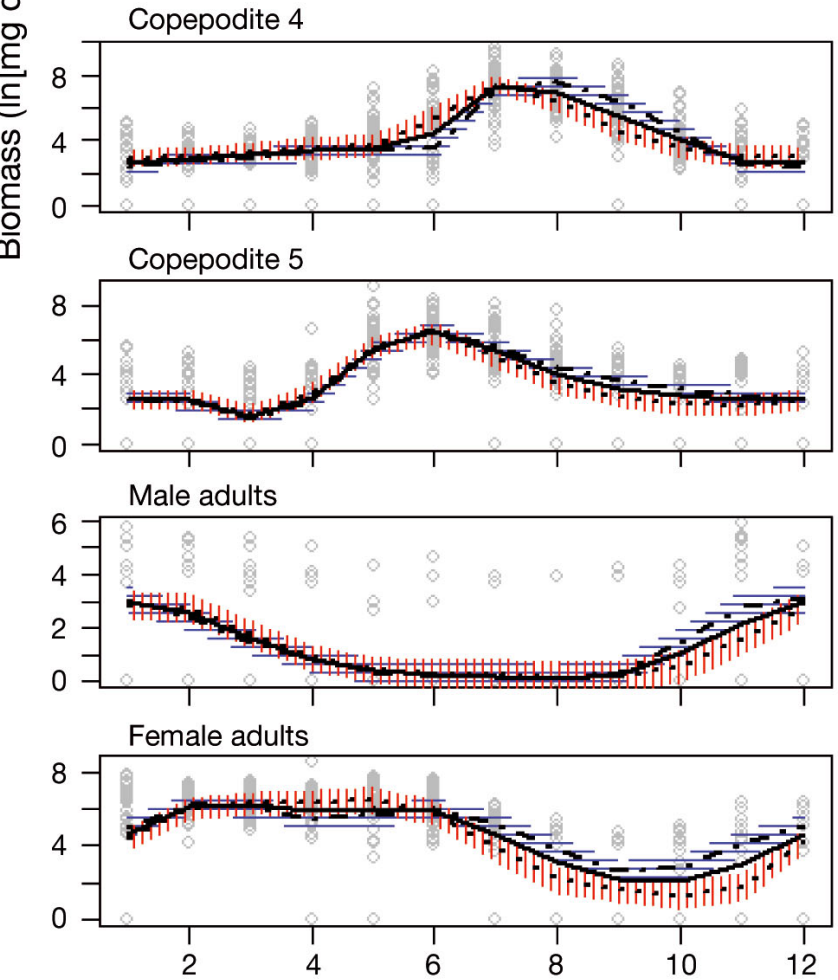

Pseudocalanus minutus

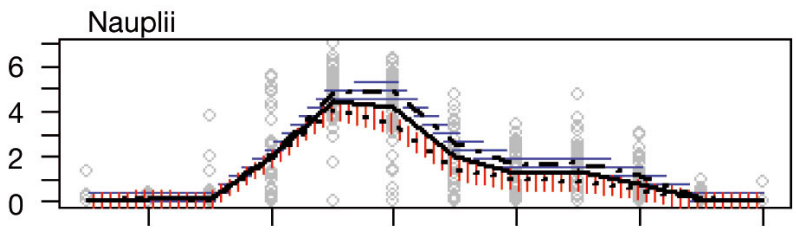

Copepodite 1
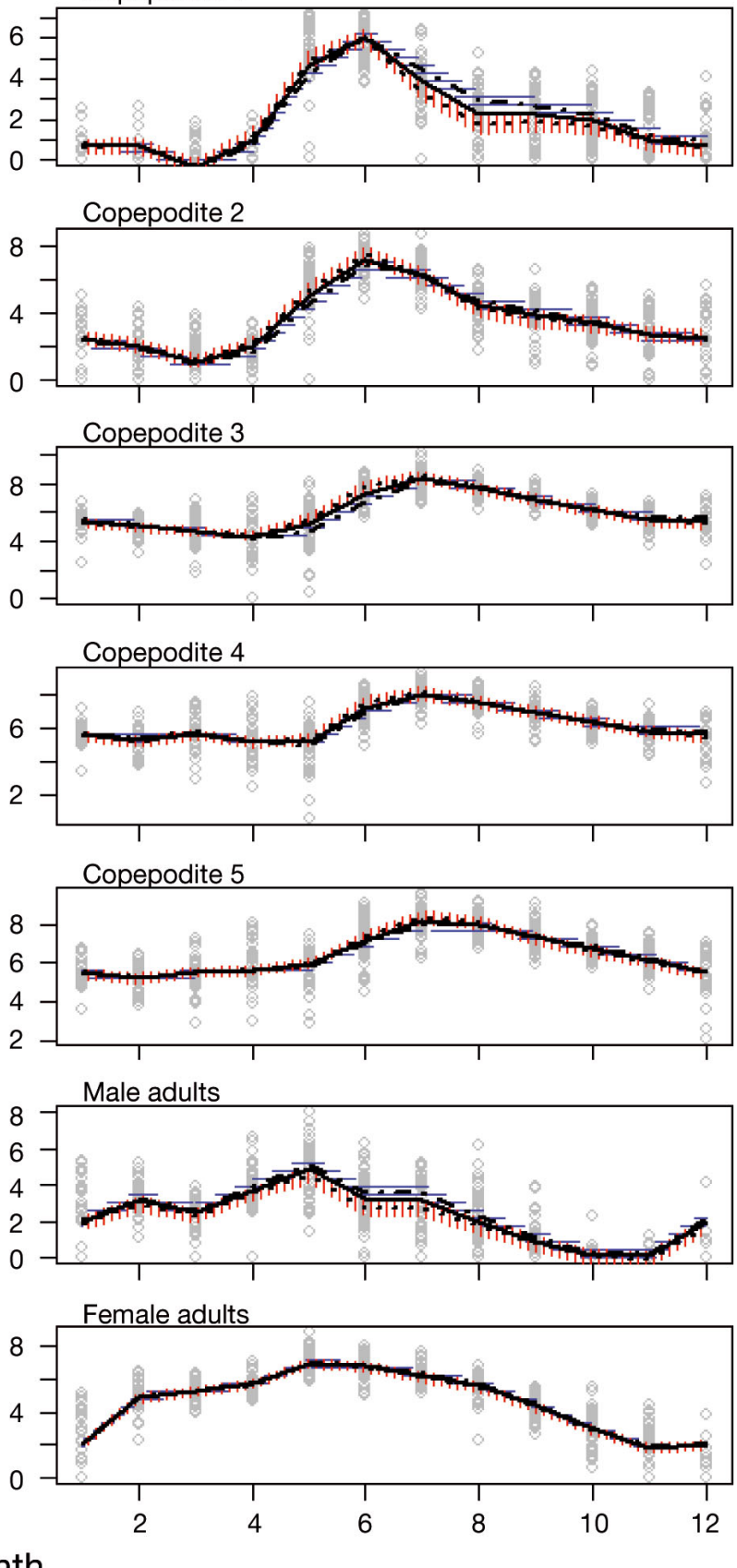

Fig. 5. Calanus glacialis, Pseudocalanus minutus. Seasonal pattern in biomass predicted for normal, cold and warm years for each individual stage of $C$. glacialis and P. minutus. Normal-year mean (solid line; representing the 50th percentile of ambient temperature for each month), warm-year mean with a $95 \%$ confidence interval (dotted line and red vertically lined area; 90 th percentile) and cold-year mean with a 95\% confidence interval (dotted/dashed line and blue horizontally lined area; 10th percentile) are shown. The original data points are included in the graphs as empty grey circles 
Table 4. Calanus glacialis, Pseudocalanus minutus. Months of largest predicted temperature effect (largest difference on a natural log scale) for each species and stage. The table shows cold (10\% percentile) and warm (90\% percentile) ambient temperatures and the corresponding predicted copepod biomass (mg dry weight $\mathrm{m}^{-2}$ ); $95 \%$ confidence intervals in parentheses. Difference: the proportional difference in predicted biomass from the cold to the warm temperatures

\begin{tabular}{|c|c|c|c|c|c|c|}
\hline Stage & $\begin{array}{l}\text { Month } \\
\text { of year }\end{array}$ & $\begin{array}{c}10 \% \text { temp. } \\
\left({ }^{\circ} \mathrm{C}\right)\end{array}$ & $\begin{array}{c}90 \% \text { temp. } \\
\left({ }^{\circ} \mathrm{C}\right)\end{array}$ & $\begin{array}{c}10 \% \text { biomass } \\
\left(\mathrm{mg} \text { dry wt } \mathrm{m}^{-2} \text { ) }\right.\end{array}$ & $\begin{array}{l}90 \% \text { biomass } \\
\left(\mathrm{mg} \text { dry wt } \mathrm{m}^{-2} \text { ) }\right.\end{array}$ & $\begin{array}{l}\text { Diff. } \\
(\%)\end{array}$ \\
\hline \multicolumn{7}{|l|}{ Calanus glacialis } \\
\hline Nauplii & 5 & 0.0 & 4.0 & $8.8(6.3-12.3)$ & $30.8(22.9-41.5)$ & 249 \\
\hline Copepodite 1 & 5 & -0.4 & 2.3 & $1.1(0.8-1.5)$ & $16.4(11.7-23.2)$ & 1370 \\
\hline Copepodite 2 & 5 & -0.4 & 2.3 & $1.4(1.0-1.8)$ & $7.2(5.2-7.2)$ & 435 \\
\hline Copepodite 3 & 6 & 1.1 & 4.8 & $62.6(45.1-87.0)$ & $287.1(201.9-408.4)$ & 359 \\
\hline Copepodite 4 & 6 & -0.3 & 2.0 & $32.9(16.6-65.1)$ & $219.0(113.6-422.5)$ & 566 \\
\hline Copepodite 5 & 9 & 0.6 & 2.7 & $38.4(23.6-62.5)$ & $14.3(8.6-23.6)$ & -63 \\
\hline Adult males & 11 & 0.6 & 2.8 & $16.3(9.4-28.5)$ & $4.8(2.8-8.5)$ & -70 \\
\hline Adult females & 11 & 0.6 & 2.8 & $62.3(29.9-129.8)$ & $5.6(2.7-11.8)$ & -91 \\
\hline Total biomass & 9 & 0.6 & 2.7 & 759.7 (528.6-1091.8) & $164.0(115.8-232.2)$ & -78 \\
\hline \multicolumn{7}{|c|}{ Pseudocalanus minutus } \\
\hline Nauplii & 6 & 2.7 & 7.4 & $138.7(90.9-211.7)$ & $30.1(19.8-45.7)$ & -78 \\
\hline Copepodite 1 & 8 & 7.3 & 14.4 & $18.4(11.8-28.8)$ & $5.6(3.6-8.6)$ & -69 \\
\hline Copepodite 2 & 5 & 0.0 & 4.0 & $96.9(60.6-154.9)$ & $228.5(146.9-355.3)$ & 136 \\
\hline Copepodite 3 & 6 & 1.1 & 4.8 & $888.7(615.1-1284.0)$ & $2531.6(1738.6-3686.4)$ & 185 \\
\hline Copepodite 4 & 6 & -0.3 & 2.0 & $1048.2(718.1-1530.1)$ & $1921.6(1284.2-2875.3)$ & 83 \\
\hline Copepodite 5 & 7 & 1.2 & 6.0 & $2968.9(2227.7-3956.5)$ & $4344.8(3170.7-5953.8)$ & 46 \\
\hline Adult males & 6 & -0.3 & 2.0 & $37.4(24.0-58.2)$ & $15.6(9.8-24.8)$ & -58 \\
\hline Adult females & 8 & 1.5 & 8.6 & $316.6(235.4-425.7)$ & $243.5(177.0-334.8)$ & -23 \\
\hline Total biomass & 6 & 1.1 & 4.8 & 7555.1 (6138.5-9299.0) & 9735.5 (7879.9-12028.0) & 29 \\
\hline
\end{tabular}

ized by freshening of the upper water layer in spring, these changes are relatively short and mainly affect the topmost meters of the water layer that active swimmers can avoid.

On an annual scale, we found no significant correlations between temperature and copepod biomass. However, when analyzing the data on a monthly scale, temperature was found to have significant effects on the dynamics of both copepod species, although for Pseudocalanus minutus these effects were more subtle and only observable when exploring the dynamics of individual life stages. In warm years, Calanus glacialis total biomass is higher in spring and lower in autumn compared to cold years (Fig. 4a). Similar shifts suggesting earlier seasonal cycles in warm years have been found in many environments and taxa, including marine zooplankton (Richardson 2008). When comparing the seasonal patterns predicted for cold and warm years (corresponding to the 10th and 90th temperature percentiles, respectively), we found that the spring increase in C. glacialis biomass in cold years is delayed by approximately $25 \mathrm{~d}$, whereas the autumn decline is delayed by about $35 \mathrm{~d}$ (Fig. 4a). This shift is not mirrored at the life stage level. In warm years, the biomass of the younger life stages increases earlier in spring, resulting in 3-fold to $>10$-fold higher biomasses of nauplii and copepodite stages $\mathrm{C} 1$ to $\mathrm{C} 3$ in May and June compared to cold years (Table 4).
However, this earlier increase in spring is not followed by an earlier decline later in summer, i.e. the timing of the late-summer declines in biomass of nauplii and $\mathrm{C} 1$ to $\mathrm{C} 3$ is similar in warm and cold years (Fig. 5). The reduction of total biomass in autumn is a result of reduced biomass of the older copepodite stages; only C4 of C. glacialis shows both a late-summer decline and an increase in spring, when their population is comprised of both over-wintered and newly hatched copepodites (D. Martynova et al. unpubl. data). The increased biomass of the young life stages of $C$. glacialis in spring is likely caused by increased egg production and/or increased juvenile survival in the spring months of warm years, as a result of earlier ice melt and the associated iceedge bloom during these years. Faster development at warm temperatures (Gillooly 2000) may have also contributed to the earlier appearance of young life stages in spring. Our results further suggest that $C$. glacialis continues to reproduce and that conditions remain favorable for juvenile survival until approximately the same time of year in warm and cold years, suggesting higher total production of young-of-theyear in warm years. We believe that the subsequent reduction in the biomass of the older copepodite stages (including adults) in autumns of warm years was not caused by higher mortality, but rather by migration to deep cold-water layers below the thermocline, as described previously (Kosobokova 1999). 
Cold-water refuges in deeper water layers probably enable $C$. glacialis to cope with warmer temperatures while they take advantage of the generally higher abundances of phytoplankton higher up in the water column (Pertsova \& Kosobokova 2010). That the Arctic species C. glacialis responds well and increases its biomass when faced with increasing temperatures is in accordance with previous results from work in the same geographical location (Pertsova \& Kosobokova 2010).

For Pseudocalanus minutus, we found that the effects of temperature on different life stages partly cancelled each other out. In warm years, the biomasses of nauplii and $\mathrm{C} 1$ decline earlier, resulting in 3 - to 5 -fold reductions from June to August compared to cold years (Table 4). We also observed a 2-fold reduction in the biomass of adult males during the same period. Furthermore, in warm years, the biomasses of $\mathrm{C} 2$ and $\mathrm{C} 3$ increase earlier, resulting in 2to 3-fold increases from May to June. Because of the dominance of the older copepodite stages in terms of biomass, these increases are enough to compensate for the reductions in the other life stages. The seasonal pattern in the total biomass is therefore not significantly different in warm compared to cold years. Similar stage-dependent temperature effects have previously been shown on metabolic rates in $C$. glacialis (Tande 1988). On the whole, P. minutus appeared in our study to be much less sensitive to temperature variations than Calanus glacialis, both on aggregated scales and when looking at the seasonal development of the individual life stages. This is consistent with the wider temperature range of the Arctic-boreal P. minutus (-1.8 to $\left.15.5^{\circ} \mathrm{C}\right)$, compared to that of the Arctic C. glacialis ( -0.39 to $4.86^{\circ} \mathrm{C}$ ) (Prygunkova 1974, Zubakha \& Usov 2004). The temperature effects found for P. minutus (Table 3) suggest slightly earlier development in warm years (Figs. 4 \& 5). Earlier development in warm years is consistent with temperature effects on metabolic rates, although other factors, such as phenological changes in the phytoplankton and in predator populations, may also come into play. We note that the total production of $\mathrm{C} 2$ and $\mathrm{C} 3$ of $P$. minutus is probably higher in warm years (Fig. 5), consistent with higher earlylife survival when development is faster. This increased production appears not to be translated into increased biomass of older life stages at the study site, possibly because of higher mortality of the older copepodites in warm years.

The effect of climate variability on the phenology of marine populations has been a topic of considerable research effort during recent years. It has been observed that non-synchronous phenological changes in predator and prey populations affect the strength of their interaction through match-mismatch dynamics (Cushing 1990, Durant et al. 2005). Our results indicate that phenological changes in plankton species may be more complex than is often thought. This complexity has implications for trophic interactions. Fish species in temperate environments have evolved specific life cycles so that the food requirements of their larvae and juveniles match the seasonal development of the available prey. For example, the larvae of Atlantic cod Gadus morhua typically feed on nauplii and copepodite stages of Calanus finmarchicus of increasing size as they grow, so that the same cohort of copepods may sustain the fish for most of their larval life (Cushing 1995). Effects of climate on such predator-prey interactions are best understood through analysis of stage-resolved copepod data. For other purposes, however, analysis of the total biomass may be ecologically more relevant. Both Calanus glacialis and Pseudocalanus minutus play significant roles in the diet of White Sea cod Gadus morhua marisalbi and White Sea herring Clupea harengus marisalbi, especially during their reproduction (herring) and larval growth (both species) periods (Slonova 1977, Gerasimova \& Podrazhanskaya 1991). In the White Sea, we found that the young life stages of C. glacialis are available for longer periods during warm years, while the older life stages disappear from the study site earlier in autumn. The implications for predators of C. glacialis depend on several factors, including their mobility (and ability to follow the possible migrations of C. glacialis) and diet range. A main point is that these implications are very different from what one would infer from the phenological analysis of total biomass of C. glacialis, which suggested that warming only affected the timing of the seasonal cycle. For P. minutus, we found that the youngest life stages are available for shorter periods in warm years, while the intermediate (but not the oldest) life stages are available for longer periods. Again, the implications for possible predators on $P$. minutus differ from what would be inferred from analysis of the phenology of total biomass, which suggested no effects of warming.

\section{CONCLUSIONS}

Our study illustrates how qualitatively different conclusions about the effects of climate on population, and, indirectly, on ecosystem dynamics may be 
drawn depending on the scale of the analysis, both in terms of time resolution (monthly vs. annual) and in terms of life-stage resolution (individual life stages vs. total biomass). Long time series with high resolution are rare, and studies therefore often base their conclusions on 'coarser' data. While unavoidable, it should be kept in mind that some biologically important dimensions may then be missed.

Acknowledgements. This work was supported by the Norwegian Research Council's 'NORKLIMA' program ('ARCWARM' project) and funding to the 'ADMAR' project. Research at the White Sea Biological Station has been supported since 2002 by the ongoing Basic Research Program of the Russian Academy of Sciences ('Biodiversity and dynamics of gene pools', sub-program 'Biodiversity', theme 'Investigation of climate impact on dynamics of zooplankton and littoral benthos biodiversity in the White Sea'). We thank Dr. Regina V. Prygunkova for the copepod weight data. Arthur Bass improved our English.

\section{LITERATURE CITED}

Beaugrand G, Brander KM, Lindley JA, Souissi S, Reid PC (2003) Plankton effect on cod recruitment in the North Sea. Nature 426:661-664

Berger V, Naumov A, Zubaha M, Usov U, Smolyar I, Tatusko R, Levitus S (2003) 36-Year time series (1963-1998) of zooplankton, temperature and salinity in the White Sea. United States Government Printing Office, Washington, DC

Burnham KP, Anderson DR (2002) Model selection and multimodel inference: a practical information-theoretic approach. Springer, New York, NY

$>$ Cushing DH (1990) Plankton production and year-class strength in fish population: an update of the match/mismatch hypothesis. Adv Mar Biol 26:249-293

Cushing DH (1995) Population production and regulation in the sea: a fisheries perspective. Cambridge University Press, Cambridge

Daase M, Vik JO, Bagøien E, Stenseth NC, Eiane K (2007) The influence of advection on Calanus near Svalbard: statistical relations between salinity, temperature and copepod abundance. J Plankton Res 29:903-911

Daufresne M, Lengfellner K, Sommer U (2009) Global warming benefits the small in aquatic ecosystems. Proc Natl Acad Sci USA 106:12788-12793

- Durant JM, Hjermann DØ, Anker-Nilssen T, Beaugrand G, Mysterud A, Pettorelli N, Stenseth NC (2005) Timing and abundance as key mechanisms affecting trophic interactions in variable environments. Ecol Lett 8:952-958

Escribano R, McLaren IA (1992) Testing hypotheses of exponential growth and size-dependent molting rate in two copepod species. Mar Biol 114:31-39

Falk-Petersen S, Pavlov V, Timofeev S, Sargent JR (2007) Climate variability and possible effects on arctic food chains: the role of Calanus. In: Ørbæk JB, Kallenborn R, Tombre I, Hegseth EN, Falk-Petersen S, Hoel AH (eds) Arctic alpine ecosystems and people in a changing environment. Springer, Heidelberg

Frost BW (1989) A taxonomy of the marine calanoid copepod genus Pseudocalanus. Can J Zool 67:525-551
Gerasimova OV, Podrazhanskaya SG (1991) Feeding conditions and features of trophic interactions of the White Sea commercial fish species. Biotopical peculiarities of distribution of marine commercial species. VNIRO, Moscow (in Russian)

Gillooly JF (2000) Effect of body size and temperature on generation time in zooplankton. J Plankton Res 22: 241-251

Harris RP, Wiebe PH, Lenz J, Skjoldal HR, Huntley M (eds) (2000) ICES zooplankton methodology manual. Academic Press, San Diego, CA

> Hopper AF (1960) The resistance of marine zooplankton of the Caribbean and South Atlantic to changes in salinity. Limnol Oceanogr 5:43-47

Jaschnov WA (1970) Distribution of Calanus species in the seas of the Northern Hemisphere. Int Rev Gesamten Hydrobiol 55:197-212

> Ji R, Edwards M, Mackas DL, Runge JA, Thomas AC (2010) Marine plankton phenology and life history in a changing climate: current research and future directions. J Plankton Res 32:1355-1368

- Klein Breteler WCM, Gonzalez SR (1988) Influence of temperature and food concentration on body size, weight and lipid content of two calanoid copepod species. Hydrobiologia 167-168:201-210

Koenker R (2010) Quantreg: quantile regression. R package Version 4.53.http://CRAN.R-project.org/package=quantreg

> Kosobokova KN (1999) The reproductive cycle and life history of the Arctic copepod Calanus glacialis in the White Sea. Polar Biol 22:254-263

Lance J (1962) Effects of water of reduced salinity on the vertical migration of zooplankton. J Mar Biol 42:131-154

> Mackas DI, Beaugrand G (2010) Comparison of zooplankton time series. J Mar Syst 79:286-304

Melnikov IA, Dikarev SN, Egorov VG, Kolosova EG, Zhitina LS (2005) Structure of the coastal ice ecosystem in the zone of sea-river interactions. Okeanologia 45:542-550

> Munk P (1997) Prey size spectra and prey availability of larval and small juvenile cod. J Fish Biol 51:340-351

> Pertsova NM, Kosobokova KN (2010) Interannual and seasonal variation of the population structure, abundance, and biomass of the arctic copepod Calanus glacialis in the White Sea. Oceanology 50:531-541

Prygunkova RV (1970) Seasonal and year-to-year changes of zooplankton in Chupa Inlet of the White Sea. PhD thesis, Zoological Institute, Russian Academy of Sciences, Leningrad (in Russian)

Prygunkova RV (1974) Some features of zooplankton seasonal changes in Chupa Inlet, the White Sea. Seasonal changes in the White and Barents Seas. Nauka, Leningrad (in Russian)

Pyper BJ, Peterman RM (1998) Comparison of methods to account for autocorrelation in correlation analyses of fish data. Can J Fish Aquat Sci 55:2127-2140

Quenouille MH (1952) Associated measurements. Butterworths, London

R Development Core Team (2010) R: a language and environment for statistical computing. R Foundation for Statistical Computing, Vienna. www.R-project.org

- Richardson AJ (2008) In hot water: zooplankton and climate change. ICES J Mar Sci 65:279-295

Slonova SA (1977) Feeding of the White Sea herring Clupea harengus maris-albi Berg. Russ J Ichthyol 17:1077-1082 (in Russian)

Søreide JE, Leu E, Berge J, Graeve M, Falk-Petersen S 
(2010) Timing of blooms, algal food quality and Calanus glacialis reproduction and growth in a changing Arctic. Glob Change Biol 16:3154-3163

Tande KS (1988) The effects of temperature on metabolic rates of different life stages of Calanus glacialis in the Barents Sea. Polar Biol 8:457-461

Tsyban AV (ed) (1980) Methods of biological analysis of seawater and bottom sediments. Gidrometeoizdat, Leningrad (in Russian)

Usov NV (2011) Zooplankton dynamics during winter in ice-covered sea by the example of coastal zone of the White Sea. Bull Saint-Petersburg Univ Ser 3 Biol 3:3-14 (in Russian)

Editorial responsibility: Edward Durbin, Narragansett, Rhode Island, USA
Walther GR, Post E, Convey P, Menzels A and others (2002) Ecological responses to recent climate change. Nature 416:389-395

Wassmann P, Duarte CM, Agustí S, Sejr MK (2011) Footprints of climate change in the Arctic marine ecosystem. Glob Change Biol 17:1235-1249

Wood SN (2006) Generalized additive models: an introduction with R. Chapman and Hall/CRC, Boca Raton, FL

Zhadin VI (1960) Methods of hydrobiological investigations. Vysshaya Shkola, Moscow (in Russian)

Zubakha MA, Usov NV (2004) Optimum temperatures for common zooplankton species in the White Sea. Russ J Mar Biol 30:293-297

Submitted: January 26, 2012; Accepted: July 16, 2012

Proofs received from author(s): October 26, 2012 